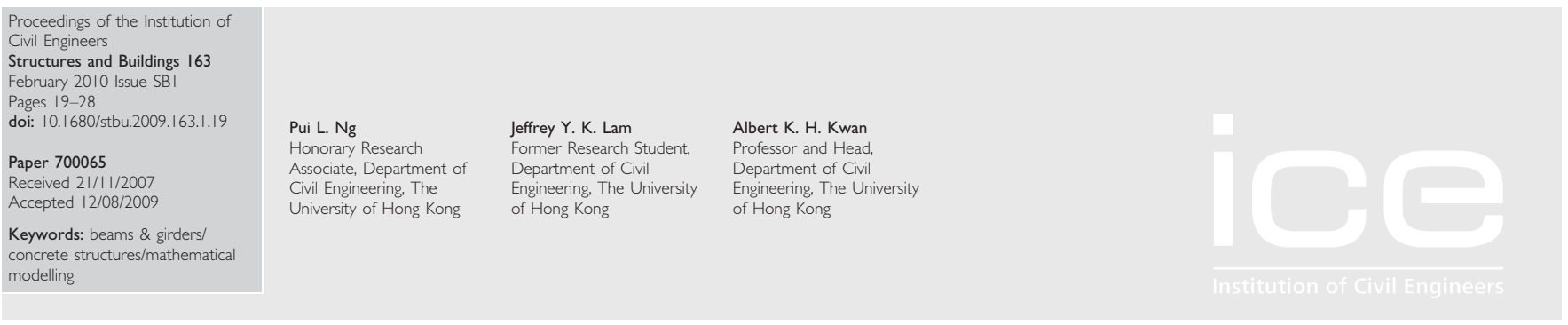

\title{
Tension stiffening in concrete beams. Part I: FE analysis
}

\author{
P. L. Ng PhD, J. Y. K. Lam PhD and A. K. H. Kwan PhD, MICE, CEng
}

\begin{abstract}
Although after cracking, concrete has negligible tension capacity, the intact concrete between cracks within the tension zone of a reinforced concrete beam can still develop significant tensile stresses to contribute to the flexural stiffness of the concrete beam. Such a tension stiffening effect in a flexural member is not quite the same as that in an axial member because the tensile stresses in a cracked flexural member are induced not only by the steel reinforcement-concrete bond but also by the curvature of the flexural member. In this study, the tensile stresses developed in cracked concrete beams are analysed using a finite-element (FE) model that takes into account the non-linear biaxial behaviour of the concrete and the non-linear bond stress-slip behaviour of the steel reinforcement-concrete interface. Based on the numerical results so obtained, a tensile stress block is proposed for section analysis of the momentcurvature curves of reinforced concrete beams at both the uncracked and cracked states. It will be shown in part $\mathbf{2}$ of this paper that the tensile stress block may also be used for member analysis of the load-deflection curves of concrete beams without resorting to FE analysis.
\end{abstract}

\section{INTRODUCTION}

In a reinforced concrete member, the stiffness of the concrete decreases after cracking but does not drop to zero because the uncracked concrete between adjacent cracks is still able to carry some tensile stresses to contribute to the overall stiffness of the member. This phenomenon is called tension stiffening. It occurs in both axial and flexural members. In axial members, such as struts subjected to uniaxial loads and panels subjected to biaxial loads, tensile stresses are induced in the concrete between cracks mainly by the stress transfer through the steel reinforcement-concrete bond. Extensive studies on tension stiffening in axial members have been carried out, including experimental investigations (Jiang et al., 1984; Wollrab et al., 1996), theoretical modelling (Floegl and Mang, 1982; Gupta and Maestrini, 1989; Wu et al., 1991; Choi and Cheung, 1996) and the development of tensile stress blocks (Link et al., 1989; Gupta and Maestrini, 1990; Massicotte et al., 1990; Fields and Bischoff, 2004).

In flexural members, tensile stresses are induced in the concrete between cracks not only by the stress transfer through the steel reinforcement-concrete bond but also by the shearing action of the curvature of the flexural member. In other words, there are two mechanisms that induce tensile stresses in the concrete of a cracked flexural member. The first mechanism, by which the stress transfer through the bond induces tensile stresses, is similar to that in a cracked axial member, as depicted in Figure 1(a). The second mechanism, by which the shearing action of the curvature induces tensile stresses, is like that of a short length of unreinforced concrete beam between two adjacent cracks subjected to curvature, as depicted in Figure 1(b) which shows that near the cracks, the plane sections no longer remain plane after cracking and shear stresses are developed to pull the uncracked concrete in the tension zones thereby inducing significant tensile stresses in the uncracked concrete. Hence, tension stiffening in flexural members is not the same as that in axial members.

Since the shearing action of curvature mentioned above is not yet common knowledge, further explanation is given in this paper. Basically, at locations near the cracks, vertical fibres (i.e. fibres that are initially vertical) in the tension zones are no longer perpendicular to horizontal fibres (fibres that are initially horizontal). Significant shear strains and stresses are developed at the centroidal axis near the cracks. The shear stresses pull the tension zones near the cracks so that at a certain distance away from the cracks, the tension zones develop tensile stresses as in uncracked sections. This is like the shear lag near cracked concrete, as was pointed out by Hughes (see Figure 2 of Hughes (2008)). Alternatively, the action may be visualised as the development of shear stresses to maintain equilibrium between the uncracked and cracked sections. At the uncracked sections, tensile stresses develop due to curvature of the member, while only negligible tensile stresses develop at the cracked sections. So, between an uncracked section and a cracked section, there must be horizontal shear stresses developed along the centroidal axis to balance the difference in horizontal tensile forces. Without curvature, as in an axial member, no such tensile stresses due to curvature would be developed. That is why the authors have chosen to call this 'the shearing action of curvature'.

There have been relatively few reported studies on the tension stiffening in flexural members compared with that in axial members. Two alternative methods of accounting for the tension stiffening in flexural members have been developed. The first method aims at a direct evaluation of momentcurvature curves, while the second attempts the development 


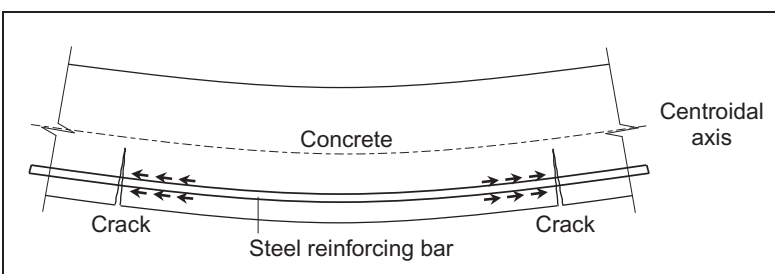

(a)

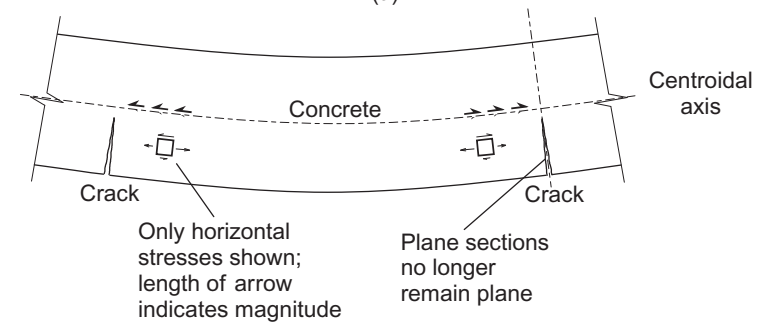

(b)

Figure I. Tension stiffening in a flexural member: (a) stress transfer through bond; (b) shearing action of curvature

of tensile stress blocks. For the furst method, Creazza and Di Marco (1993) and Polak and Blackwell (1998) developed theoretical models to evaluate moment-curvature curves. Piyasena et al. (2002) carried out finite-element (FE) analysis of the variation of curvature between adjacent cracks, from which the moment-mean curvature curve could be derived. However, despite the simplifying assumptions made, these theoretical models are far too complicated for practical applications. For this reason, design codes CEB-FIP Model Code 1990 (CEB, 1993) and ACI building code (ACI, 2008) instead give empirical formulas for a quick and approximate evaluation of the moment-curvature curves.

For the second method, several tensile stress blocks have been developed. As full-field measurement of the tensile stresses in a cracked concrete beam is extremely difficult, tensile stress blocks are generally developed by proposing a certain tensile stress block with unknown parameters and then determining the unknown parameters by curve-fitting of the theoretical moment-curvature or load-deflection curves with experimental results. Gilbert and Warner (1978) considered three alternative tensile stress blocks with different descending branches. Prakhya and Morley (1990) adopted a tensile stress block comprising a linear ascending branch and a non-linear descending branch, while Kaklauskas and Ghaboussi (2001) adopted a tensile stress block composed of a linear ascending branch and a linear descending branch. Scott (1983) and Beeby et al. (2005) proposed tensile stress blocks each comprising multi-linear ascending and descending branches. Recently, Torres et al. (2004) adopted the strategy of determining the unknown parameters by curve-fitting with empirical momentcurvature curves given in a design code. The tensile stress block given in BS 8110 (BSI, 1985) is in the form of a linear ascending curve with no descending branch at all. It is clear then that all these tensile stress blocks differ widely and it is difficult to judge which is more appropriate.

It should be noted that although the tensile stress block is normally given in the form of a stress-strain curve, it is not the same as the tensile stress-strain curve of the concrete material itself. The tensile stress block has been given in such a form solely for the purpose that it may be applied at all stress states. In a cracked concrete beam, the tensile stress induced in the concrete between two adjacent cracks varies not only with the depth but also along the beam axis. At a cracked section, the tensile stress is practically zero while at an uncracked section, the tensile stress increases with the distance from the nearest cracked section. Since the cracks are to be smeared in the structural analysis such that each beam section may be assumed to have a flexural stiffness changing smoothly with the mean curvature regardless of the actual positions and spacing of the cracks, the tensile stress block should be taken as the distribution of the mean tensile stress within the beam depth.

However, due to the difficulties involved, the tension stress fields in cracked concrete beams have never been thoroughly measured; consequently, there is still insufficient experimental data for evaluating the distribution of the mean tensile stress within the beam depth. To overcome this difficulty, the present study attempts to evaluate the tension stress fields in cracked concrete beams by FE analysis. Typical reinforced concrete beams with varying structural parameters have been analysed and the tension stress fields under different conditions obtained. This is probably the first time that the actual distribution of mean tensile stress within a beam depth has been directly determined.

\section{FINITE-ELEMENT ANALYSIS}

\section{I. Secant stiffness formulation and direct iteration} In order to extend the analysis into the post-crack and postpeak ranges within which the tangent stiffness can become undefined or negative, secant stiffness is used in the formulation of the stiffness matrices. For the non-linear analysis, an iterative procedure with the loads applied in small increments is used. At each load increment step, direct iteration using the secant stiffness of the structure is employed. With this method, the loads can be applied either directly in the form of prescribed forces or indirectly in the form of prescribed displacements at the loading points.

The above formulation and numerical procedures for developing FE codes have been used since the 1980s (Liauw and Kwan, 1982). In this particular study, the FE code used is a tailor-made and refined version for reinforced concrete members (Ng, 2007). It has been carefully validated before use.

\subsection{Modelling of concrete}

The concrete is modelled by plane stress elements, which are simply three-noded triangular constant strain elements. Its non-linear biaxial stress-strain behaviour is accounted for in terms of the equivalent uniaxial strains defined by

\begin{tabular}{|l|l|}
\hline Ia & $\boldsymbol{\varepsilon}_{\mathrm{e} 1}=\frac{1}{1-v_{1} v_{2}}\left(\boldsymbol{\varepsilon}_{1}+v_{2} \boldsymbol{\varepsilon}_{2}\right)$ \\
\hline Ib & $\boldsymbol{\varepsilon}_{\mathrm{e} 2}=\frac{1}{1-v_{1} v_{2}}\left(\boldsymbol{\varepsilon}_{2}+v_{1} \boldsymbol{\varepsilon}_{1}\right)$ \\
\hline
\end{tabular}

where $\boldsymbol{\varepsilon}_{\mathrm{e} 1}$ and $\boldsymbol{\varepsilon}_{\mathrm{e} 2}$ are the equivalent uniaxial strains, $\boldsymbol{\varepsilon}_{1}$ and $\boldsymbol{\varepsilon}_{2}$ are the principal strains, $v_{1}$ and $v_{2}$ are Poisson's ratios and 
subscripts 1 and 2 denote quantities in the respective principal directions. Each of the principal stresses $\boldsymbol{\sigma}_{1}$ and $\boldsymbol{\sigma}_{2}$ is assumed to be a single variable function of the corresponding equivalent uniaxial strain. In effect, therefore, the biaxial stress-strain relation is decomposed into two independent uniaxial stress-strain relations.

Due to biaxial effects, the tensile and compressive strengths in the principal directions are not the same as the uniaxial tensile and compressive strengths. They are determined using the biaxial strength envelope developed by Kupfer and Gerstle (1973), which consists of four distinct zones, namely the tension-tension, tension-compression, compressioncompression and compression-tension zones. To evaluate the tensile and compressive strengths in the principal directions, it is necessary first to find out within which zone the biaxial stress state falls and then locate the point on the strength envelope that will be intercepted when the biaxial stresses keep on increasing. The strength values at the intercepting point are the tensile and compressive strengths in the principal directions, denoted $\boldsymbol{f}_{\mathrm{tp}}$ and $\boldsymbol{f}_{\mathrm{cp}}$ respectively.

For any principal direction under tension, the stress-strain curve follows that of Guo and Zhang (1987), which is given by

\begin{aligned} \hline $2 \mathrm{a} & \frac{\boldsymbol{\sigma}}{\boldsymbol{f}_{\mathrm{tp}}}=1 \cdot 2\left(\frac{\boldsymbol{\varepsilon}}{\boldsymbol{\varepsilon}_{\mathrm{tp}}}\right)-0.2\left(\frac{\boldsymbol{\varepsilon}}{\boldsymbol{\varepsilon}_{\mathrm{tp}}}\right)^{6} \\ &$ for the ascending branch \end{aligned}

$2 \mathrm{\sigma} \quad \frac{\boldsymbol{\sigma}}{\boldsymbol{f}_{\mathrm{tp}}}=\left(\frac{\boldsymbol{\varepsilon}}{\boldsymbol{\varepsilon}_{\mathrm{tp}}}\right) /\left[a\left(\frac{\boldsymbol{\varepsilon}}{\boldsymbol{\varepsilon}_{\mathrm{tp}}}-1\right)^{1 \cdot 7}+\left(\frac{\boldsymbol{\varepsilon}}{\boldsymbol{\varepsilon}_{\mathrm{tp}}}\right)\right]$
for the descending branch

in which $\boldsymbol{\varepsilon}_{\text {tp }}$ is the strain at peak tensile stress and $a$ is a dimensionless coefficient equal to $0.312 \boldsymbol{f}_{\mathrm{t}}^{2}\left(\boldsymbol{f}_{\mathrm{t}}\right.$ being the uniaxial tensile strength in MPa). Since the crack tips in reinforced concrete beams are usually located near the neutral axis where the tensile stresses are small, the fracture energy of the crack tips has been neglected in the analysis.

For any principal direction under compression, the stressstrain curve follows that of Saenz (1964), which is given by

\begin{tabular}{|l|l|}
$\frac{\boldsymbol{\sigma}}{f_{\mathrm{cp}}}=$ & $\left(\frac{\boldsymbol{E}_{\mathrm{co}}}{\boldsymbol{E}_{\mathrm{cp}}}\right)\left(\frac{\boldsymbol{\varepsilon}}{\boldsymbol{\varepsilon}_{\mathrm{cp}}}\right) /$ \\
& {$\left[1+\left(\frac{E_{\mathrm{co}}}{E_{\mathrm{cp}}}-2\right)\left(\frac{\boldsymbol{\varepsilon}}{\boldsymbol{\varepsilon}_{\mathrm{cp}}}\right)+\left(\frac{\boldsymbol{\varepsilon}}{\boldsymbol{\varepsilon}_{\mathrm{cp}}}\right)^{2}\right]$}
\end{tabular}

in which $\boldsymbol{E}_{\mathrm{co}}$ is the initial elastic modulus, and $\boldsymbol{E}_{\mathrm{cp}}$ and $\boldsymbol{\varepsilon}_{\mathrm{cp}}$ are the secant modulus and strain at peak compressive stress, respectively.

For each principal direction, the principal stress $\boldsymbol{\sigma}$ is obtained by substituting the corresponding equivalent uniaxial strain as $\boldsymbol{\varepsilon}$ into Equation 2 or 3, whichever is applicable. Having evaluated the principal stresses $\boldsymbol{\sigma}_{1}$ and $\boldsymbol{\sigma}_{2}$, the secant stiffnesses $E_{\mathrm{c} 1}$ and $E_{\mathrm{c} 2}$ are calculated as $\boldsymbol{\sigma}_{1} / \boldsymbol{\varepsilon}_{\mathrm{e} 1}$ and $\boldsymbol{\sigma}_{2} / \boldsymbol{\varepsilon}_{\mathrm{e} 2}$, respectively. From these secant stiffness values, the constitutive matrix $\left[\mathrm{D}_{\mathrm{c}}^{\prime}\right]$ of the concrete in the local coordinate system, whose coordinate axes are the same as the principal directions, is derived as

$4 \quad\left[\mathrm{D}_{\mathrm{c}}^{\prime}\right]=\left[\begin{array}{ccc}\frac{E_{\mathrm{c} 1}}{1-v_{1} v_{2}} & \frac{v_{2} E_{\mathrm{c} 1}}{1-v_{1} v_{2}} & 0 \\ \frac{v_{1} E_{\mathrm{c} 2}}{1-v_{1} v_{2}} & \frac{E_{\mathrm{c} 2}}{1-v_{1} v_{2}} & 0 \\ 0 & 0 & G\end{array}\right]$

in which $\boldsymbol{G}$ is the shear modulus. Before cracking, the shear modulus is just taken as the initial elastic shear modulus $\boldsymbol{G}_{0}$. After cracking, since the principal directions are the directions perpendicular and parallel to the cracks formed, the principal directions become the cracking directions and are then fixed (i.e. no longer allowed to rotate). As the crack may still be able to transmit a small amount of shear stress by aggregate interlock, the shear modulus after cracking is taken as $\gamma \boldsymbol{G}_{0}$, in which $\gamma$ is a dimensionless shear retention factor depending on the tensile strain perpendicular to the crack, as given by He and Kwan (2001). From the above constitutive matrix, the constitutive matrix $\left[D_{c}\right]$ of the concrete in the global coordinate system is obtained simply by the usual coordinate transformation.

\subsection{Modelling of steel reinforcement}

In order to allow for bond slip between the longitudinal reinforcing bars and the surrounding concrete, the longitudinal reinforcement is modelled by discrete bar elements connected to the concrete through bond elements. The bar elements are one-dimensional elements possessing only axial stiffness. For modelling the elastic, plastic and strain hardening behaviour of the steel, the constitutive model proposed by Mander (1984) is adopted. Based on this constitutive model, the relation between the steel stress $\boldsymbol{\sigma}_{\mathrm{s}}$ and steel strain $\boldsymbol{\varepsilon}_{\mathrm{s}}$ is given by

$$
\text { 5a } \quad \boldsymbol{\sigma}_{\mathrm{s}}=\boldsymbol{E}_{\mathrm{so}} \boldsymbol{\varepsilon}_{\mathrm{s}} \text { for } \boldsymbol{\varepsilon}_{\mathrm{s}} \leqslant \boldsymbol{f}_{\mathrm{y}} / \boldsymbol{E}_{\mathrm{so}}
$$

\begin{tabular}{|c|c|c|}
\hline $5 b$ & $\boldsymbol{\sigma}_{\mathrm{s}}=\boldsymbol{f}_{\mathrm{y}}$ for $\boldsymbol{f}_{\mathrm{y}} / \boldsymbol{E}_{\mathrm{so}}<\boldsymbol{\varepsilon}_{\mathrm{s}} \leqslant \boldsymbol{\varepsilon}_{\mathrm{sh}}$
\end{tabular}

\begin{tabular}{|c|c|}
\hline $5 \mathrm{c}$ & $\boldsymbol{\sigma}_{\mathrm{s}}=\boldsymbol{f}_{\mathrm{y}}+\left(\boldsymbol{f}_{\mathrm{u}}-\boldsymbol{f}_{\mathrm{y}}\right)\left[1-\left(\frac{\boldsymbol{\varepsilon}_{\mathrm{u}}-\boldsymbol{\varepsilon}_{\mathrm{s}}}{\boldsymbol{\varepsilon}_{\mathrm{u}}-\boldsymbol{\varepsilon}_{\mathrm{sh}}}\right)^{n}\right]$ \\
& for $\boldsymbol{\varepsilon}_{\mathrm{sh}}<\boldsymbol{\varepsilon}_{\mathrm{s}} \leqslant \boldsymbol{\varepsilon}_{\mathrm{u}}$ \\
\hline
\end{tabular}

where $\boldsymbol{E}_{\mathrm{so}}$ is the initial elastic modulus, $\boldsymbol{f}_{\mathrm{y}}$ is the yield strength, $\boldsymbol{f}_{\mathrm{u}}$ is the ultimate tensile strength, $\boldsymbol{\varepsilon}_{\mathrm{sh}}$ is the strain at start of strain hardening, $\boldsymbol{\varepsilon}_{\mathrm{u}}$ is the ultimate strain and $n$ is a dimensionless parameter depending on the strain-hardening property of the steel. From the steel stress $\boldsymbol{\sigma}_{\mathrm{s}}$ and steel strain $\boldsymbol{\varepsilon}_{\mathrm{s}}$, the secant stiffness $\boldsymbol{E}_{\mathrm{s}}$ of the steel is calculated as $\boldsymbol{\sigma}_{\mathrm{s}} / \boldsymbol{\varepsilon}_{\mathrm{s}}$. With this secant stiffness, the stiffness matrix of the bar element can be obtained in the usual way (ASCE, 1982). On the other hand, the transverse reinforcement is assumed to be perfectly bonded to the concrete and modelled as smeared reinforcement (ASCE, 1982). 


\subsection{Modelling of bond}

The bond between the longitudinal reinforcement and concrete is modelled using a four-noded bond element similar to the interface element developed by Goodman et al. (1968). Each bond element is assumed to have an infinitesimally small thickness. It has two pairs of duplicated nodes. The two nodes in each pair of duplicated nodes have the same coordinates but different degrees of freedom. Between them, one is connected to the steel reinforcement while the other is connected to the concrete. The difference in displacement of the duplicated nodes in the direction of the steel-concrete interface is taken as the bond slip.

In this study, the bond stress-slip relation recommended by CEB-FIP Model Code 1990 (CEB, 1993) is employed. It is given by

\begin{tabular}{|c|c|}
\hline 6a & $\boldsymbol{T}_{\mathrm{b}}=\boldsymbol{T}_{\mathrm{p}}\left(\frac{s_{\mathrm{b}}}{s_{1}}\right)^{0.4}$ for $s_{\mathrm{b}} \leqslant s_{1}$ \\
\hline
\end{tabular}

\begin{tabular}{|c|c|}
\hline $6 \mathrm{~b}$ & $\boldsymbol{T}_{\mathrm{b}}=\boldsymbol{T}_{\mathrm{p}}$ for $s_{1}<s_{\mathrm{b}} \leqslant s_{2}$ \\
\hline
\end{tabular}

\begin{tabular}{|c|c|}
\hline $6 \mathrm{c}$ & $\boldsymbol{T}_{\mathrm{b}}=\left(\frac{s_{\mathrm{b}}-s_{2}}{s_{3}-s_{2}}\right)\left(\boldsymbol{T}_{\mathrm{f}}-\boldsymbol{T}_{\mathrm{p}}\right)+\boldsymbol{T}_{\mathrm{p}}$ \\
& for $s_{2}<s_{\mathrm{b}} \leqslant s_{3}$ \\
\hline
\end{tabular}

\begin{tabular}{|c|c|}
\hline $6 \mathrm{~d}$ & $\boldsymbol{T}_{\mathrm{b}}=\boldsymbol{T}_{\mathrm{f}}$ for $s_{3}<s_{\mathrm{b}}$ \\
\hline
\end{tabular}

in which $\boldsymbol{T}_{\mathrm{b}}$ is the bond stress, $\boldsymbol{T}_{\mathrm{p}}$ is the peak bond stress, $\boldsymbol{T}_{\mathrm{f}}$ is the residual bond stress, $s_{\mathrm{b}}$ is the bond slip, and $s_{1}, s_{2}$ and $s_{3}$ are the slip at the start of peak bond stress, slip at the end of peak bond stress and slip at the start of residual bond stress, respectively.

Initially, before bond slip occurs, the secant bond stiffness $k_{\mathrm{b}}$ is taken as $200 \mathrm{~N} / \mathrm{mm}^{3}$, as recommended by CEB-FIP Model Code 1990. After bond slip has occurred, the bond stress $\boldsymbol{T}_{\mathrm{b}}$ is determined by substituting the bond slip $s_{\mathrm{b}}$ evaluated from the nodal displacements of the bond element into the above equations and the secant bond stiffness $\boldsymbol{k}_{\mathrm{b}}$ is calculated as $\boldsymbol{T}_{\mathrm{b}} / s_{\mathrm{b}}$. Having obtained the secant bond stiffness, the stiffness matrix of the bond element in the local coordinate system may then be derived following the procedures developed by Goodman et al. (1968) with the area of the interface taken as the length of the bond element multiplied by the total perimeter of the steel reinforcing bars. Finally, the stiffness matrix of the bond element in the global coordinate system is obtained by the usual coordinate transformation.

\section{ANALYSIS OF REINFORCED CONCRETE BEAMS}

\section{I. Beams analysed}

A series of typical simply supported reinforced concrete beams having different amounts of tension reinforcement and subjected to either a single point load at mid-span or a uniformly distributed load over the entire span were analysed. All the beams analysed have a span of $6000 \mathrm{~mm}$ and a uniform cross-section of $300 \mathrm{~mm}$ breadth by $600 \mathrm{~mm}$ depth. The effective depth, that is the depth from the top of beam section to the centreline of the tension reinforcement, is $550 \mathrm{~mm}$. In each beam, the tension reinforcement is provided in the form of two main bars. Figure 2(a) shows the general layout of the beams. In order to study the effects of the amount of tension reinforcement, the tension reinforcement ratio $\rho_{\mathrm{t}}$ was varied $(0.5,1 \cdot 0,1.5$ and $2 \cdot 0 \%)$. The shear reinforcement ratio was fixed at $0 \cdot 4 \%$. In total, eight reinforced concrete beams were analysed.

The properties of the beam materials are presented in Table 1. For the steel reinforcement-concrete bond, the material parameters pertinent to deformed bars embedded in unconfined concrete recommended by CEB-FIP Model Code 1990 were adopted. Following the model code, the peak bond stress $\boldsymbol{T}_{\mathrm{p}}$ and residual bond stress $\boldsymbol{T}_{\mathrm{f}}$ are taken as $2 \cdot 0\left(\boldsymbol{f}_{\mathrm{c}}\right)^{0.5}$ and $0 \cdot 3\left(\boldsymbol{f}_{\mathrm{c}}\right)^{0.5}$, respectively.

The beams were discretised into 12 layers of FEs, as depicted by the mesh shown in Figure 2(b). During FE analysis, loading was applied in small increments to each beam as prescribed displacement when the beam was subjected to a single point load at mid-span or as prescribed force when the beam was

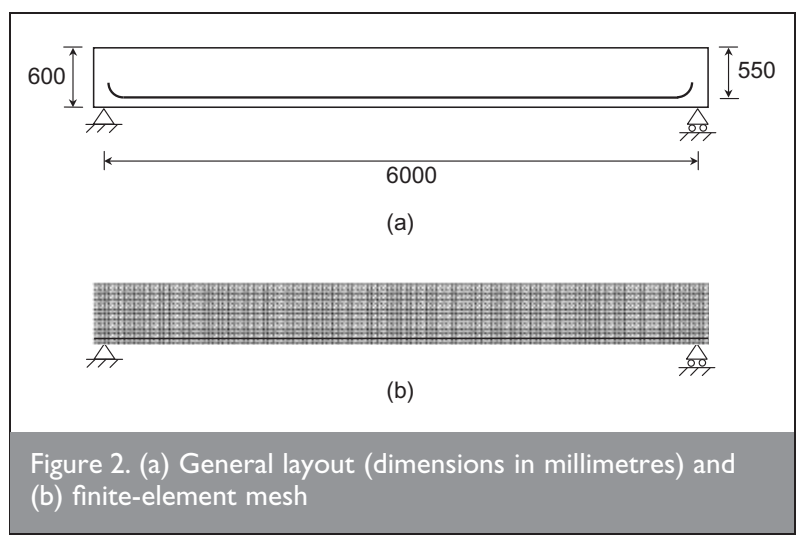

\section{Concrete}

Uniaxial tensile strength $f_{\mathrm{t}}: \mathrm{MPa}$

Poisson's ratio $v$

Steel reinforcement

Yield strength $f_{y}: M P a$

Ultimate tensile strength $f_{\mathrm{u}}: M P a$

Initial elastic modulus $E_{\mathrm{so}}$ : $\mathrm{GPa}$

Tensile strain at start of strain hardening $\boldsymbol{\varepsilon}_{\mathrm{sh}}$ : \%

Ultimate tensile strain $\boldsymbol{\varepsilon}_{\mathrm{u}}$ : \%

Steel reinforcement-concrete bond

Peak bond stress $\boldsymbol{T}_{\mathrm{p}}: \mathrm{MPa}$

Residual bond stress $\boldsymbol{T}_{\mathrm{f}}: \mathrm{MPa}$

Slip at start of peak bond stress $s_{1}: \mathrm{mm}$

Slip at end of peak bond stress $s_{2}: \mathrm{mm}$

Slip at start of residual bond stress $s_{3}: \mathrm{mm}$ 
subjected to a uniformly distributed load. At each load increment step, direct iteration was employed. The direct iteration at each load increment step was repeated until the change in secant modulus in every FE was less than $2 \cdot 0 \%$. In the analysis of each beam, about 100 load increment steps were applied until the tension reinforcement yielded and the maximum tensile strain reached $2500 \mu \varepsilon$.

\subsection{Analysis results}

The crack pattern and stress distributions in a typical reinforced concrete beam $\left(\rho_{\mathrm{t}}=0 \cdot 5 \%\right.$ and subjected to a point load at mid-span) obtained by the FE analysis are presented in Figure 3. The first crack forms at mid-span where the bending moment is largest. As the applied load increases, further cracks appear at regular spacings from previous cracks formed, as shown in Figure 3(a) for the crack pattern when the applied load is equal to $45 \%$ of the peak load.

From Figures 3(b) and 3(c), which show the stresses induced in the concrete and the tension reinforcement, it is evident that the concrete and steel stresses vary in the longitudinal direction between two adjacent cracks. Basically, at a cracked section, the tensile stress in the concrete first increases with distance from the neutral axis and then decreases to a negligible value; at an uncracked section, the tensile stress in the concrete increases with distance from the neutral axis and then remains at a certain significant value. On the other hand, the tensile stress in the tension reinforcement always reaches a local maximum value at a cracked section and decreases to a local minimum value at about halfway between two adjacent cracks.

Figure 3(d), which shows the bond stress between the tension reinforcement and the concrete, indicates that the bond stress

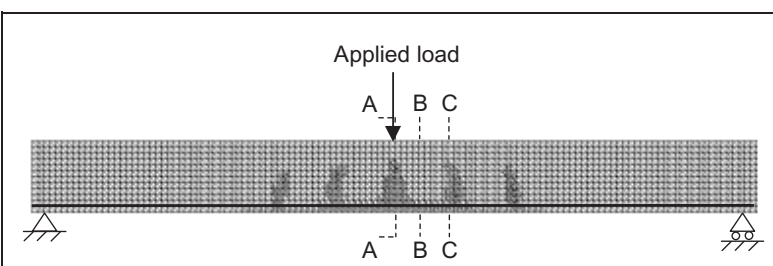

(a)

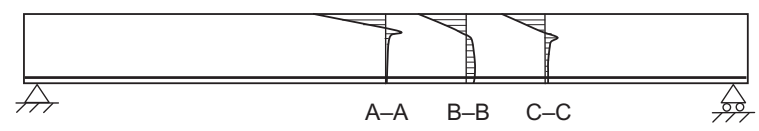

(b)

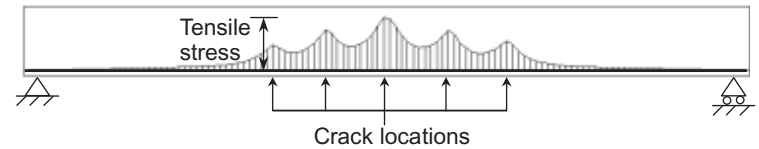

(c)

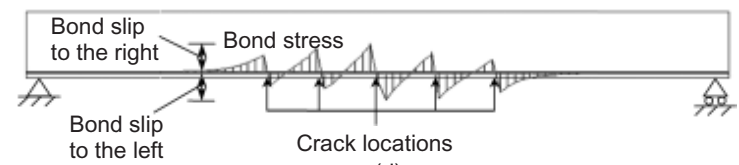

(d)

Figure 3. (a) Crack pattern $\left(\rho_{\mathrm{t}}=0.5 \%\right.$, applied load $=45 \%$ of peak load); (b) stress distribution in concrete; (c) tensile stress in reinforcement; (d) bond stress exhibits sharp changes at cracks. At the two opposite sides of a crack, the bond stresses are in opposite directions. At the lefthand side of a crack, the bond slip of the reinforcement and the bond stress acting on the concrete are to the right, but at the right-hand side, the bond slip of the reinforcement and the bond stress acting on the concrete are to the left. Consequently, the bond between the reinforcement and the uncracked concrete is always transferring tensile force to the concrete, leading to a gradual increase in the tensile stress of the concrete with distance from the nearest crack.

The tensile force transferred from the reinforcement through the bond to the concrete (calculated by adding the bond forces together) is illustrated and compared with the actual tensile force in the tension zone of the concrete for the beam with $\rho_{\mathrm{t}}=0.5 \%$ and subjected to either a point load or a uniformly distributed load in Figure 4. The tensile force transferred from the reinforcement through the bond to the concrete accounts for about $45-55 \%$ of the actual tensile force induced in the tension zone of the concrete. Hence, as explained earlier and illustrated in Figure 1, curvature of the beam should induce a significant tensile force in the tension zone of the concrete.

The load-deflection curves of the beams analysed are plotted in Figure 5. For each beam, at an applied load smaller than

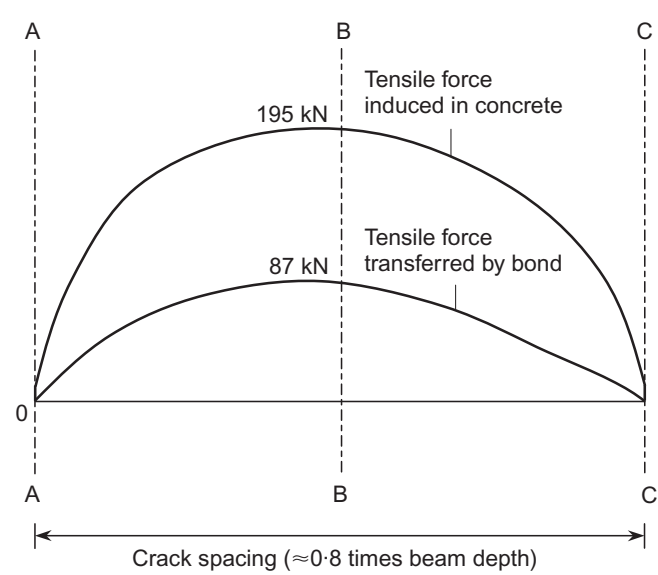

(a)

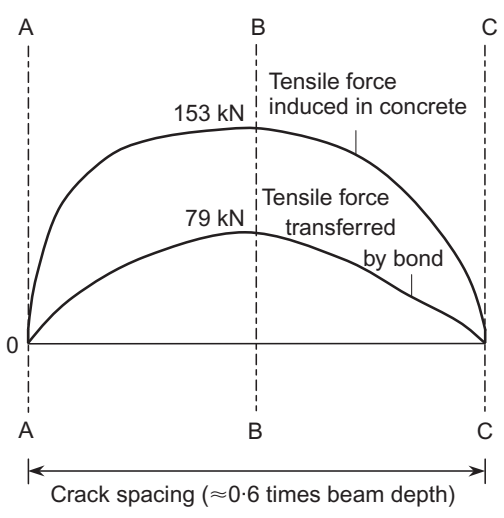

(b)

Figure 4. Tensile force transferred through the bond and tensile force induced in concrete: (a) beam subjected to point load at mid-span $\left(\rho_{\mathrm{t}}=0.5 \%\right)$; (b) beam subjected to uniformly distributed load $\left(\rho_{\mathrm{t}}=0.5 \%\right)$ 
about $20 \%$ of the peak load, the load-deflection curve is linear. As the applied load increases and when the beam eventually cracks, the gradient of the load-deflection curve decreases. However, upon further increase in applied load, when no more new cracks are formed, the gradient of the curve becomes constant until the beam starts to fail because of yielding of the tension reinforcement and crushing of concrete. At the post-peak state, all the beams exhibit ductile behaviour because they are under-reinforced.

\section{DERIVATION OF TENSILE STRESS BLOCK}

\section{I. Tension stress field}

The general shapes of the tension stress fields within cracked and uncracked sections were shown in Figure 3. For simply a presentation of numerical results, the tensile stress in the concrete obtained directly by FE analysis can be plotted against depth. However, the variation of the tensile stress in concrete with depth changes dramatically with the stress state. To avoid dealing with many different tensile stress-depth curves at different stress states, it is better to plot the tensile stress against the 'theoretical tensile strain'. The theoretical tensile strain is not the true tensile strain of the concrete, but is the tensile strain value evaluated during structural analysis (more specifically, section analysis for deriving the momentcurvature curve) with the cracks smeared so that the flexural stiffness of the beam section changes smoothly with the mean curvature.

In theory, the theoretical tensile strain may be evaluated

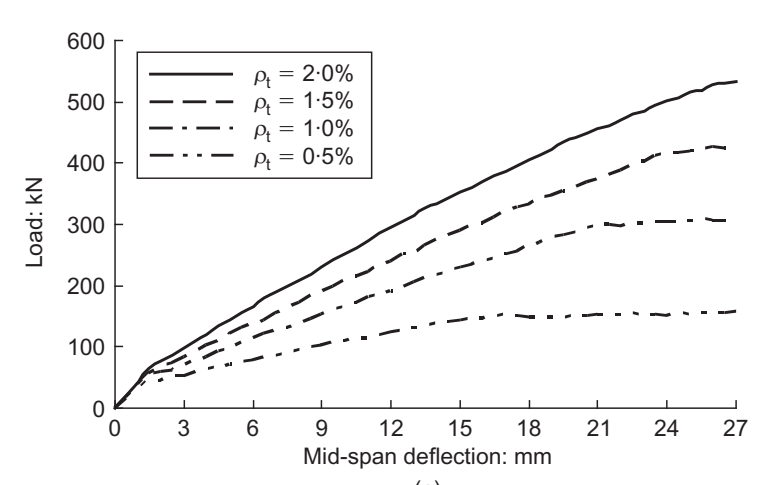

(a)

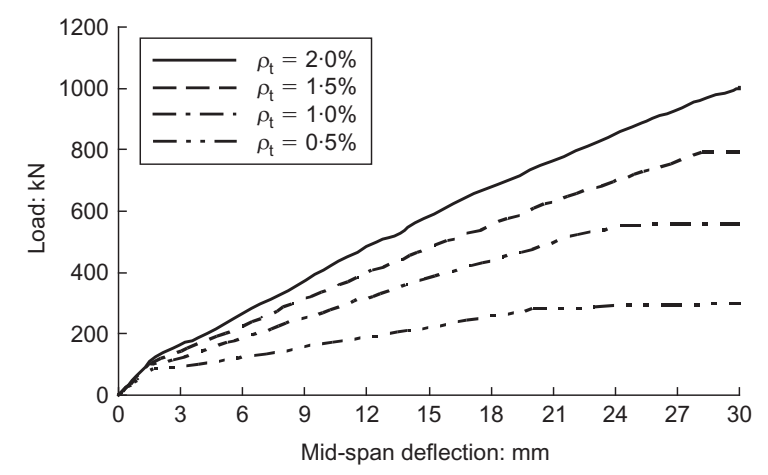

(b)

Figure 5. Load-deflection curves: (a) beams subjected to point load at mid-span; (b) beams subjected to uniformly distributed load simply as $\phi z$, where $\phi$ is the mean curvature and $z$ is the depth from the neutral axis. However, after cracking, the curvature fluctuates between adjacent cracks. To evaluate the mean curvature, the local fluctuation of the curvature has to be smoothed. Here, the mean curvature at a beam section is evaluated from FE analysis results by considering a short length of the beam starting and ending at one beam depth to each side of the beam section. The deflection of this short length of beam is fitted with a cubic polynomial curve and then the polynomial curve is differentiated twice with respect to the length to obtain the smoothened curvature value as the mean curvature at the beam section. Having obtained the mean curvature at each beam section, the tensile stress in the concrete may then be plotted against the theoretical tensile strain. As expected, the variation of tensile stress with theoretical tensile strain still changes with the stress state, but to a much lesser extent.

Also as expected, the variation of tensile stress with theoretical tensile strain is quite different at different sections, depending on whether the section is cracked or uncracked and the distance from the nearest cracked section. As the cracks are to be smeared in the structural analysis, it is the 'mean tensile stress' that is of greater interest. The mean tensile stress is the smoothed tensile stress in the concrete with local fluctuation in the longitudinal direction removed. Here, the variation of the mean tensile stress with theoretical tensile strain at a beam section is obtained from FE analysis by considering a short segment of the cracked beam starting and ending at a half crack spacing to each side of the beam section. The short segment has the same length as the crack spacing and is divided into as many sections as possible. First, the variation of tensile stress with theoretical tensile strain is plotted for each section. Then the mean tensile stress at each theoretical tensile strain level is evaluated as the root-mean-square of the tensile stress values of the sections at the theoretical tensile strain level being considered. Root-mean-square is adopted as the mean because this will result in the same strain energy after stress smoothing.

The variation of the mean tensile stress at the mid-span section with the theoretical tensile strain so obtained by the above method for beams with $\rho_{\mathrm{t}}=0.5 \%$ is plotted in Figure 6 . The figure shows that, before cracking (applied load $=15 \%$ of peak load), the mean tensile stress - theoretical tensile strain curve of each beam is basically a straight line ascending to a certain peak value not higher than the tensile strength of the concrete. When the beam has cracked slightly (applied load $=20 \%$ of peak load), the linear ascending branch of the curve reaches a slightly lower peak value than before and a short descending branch emerges. When the beam has cracked more extensively (applied load $\geqslant 30 \%$ of peak load), the ascending branch becomes non-linear and reaches a peak value approximately equal to half the tensile strength of concrete while the descending branch extends to form a tail ending at a fairly large theoretical tensile strain.

In general, tension stiffening is most significant when the beam is under the servicing condition, that is when the applied load is equal to about $30-60 \%$ of the peak load. Within this range of applied load, the mean tensile stress-theoretical tensile strain curve changes slightly with the stress state. Nevertheless, 


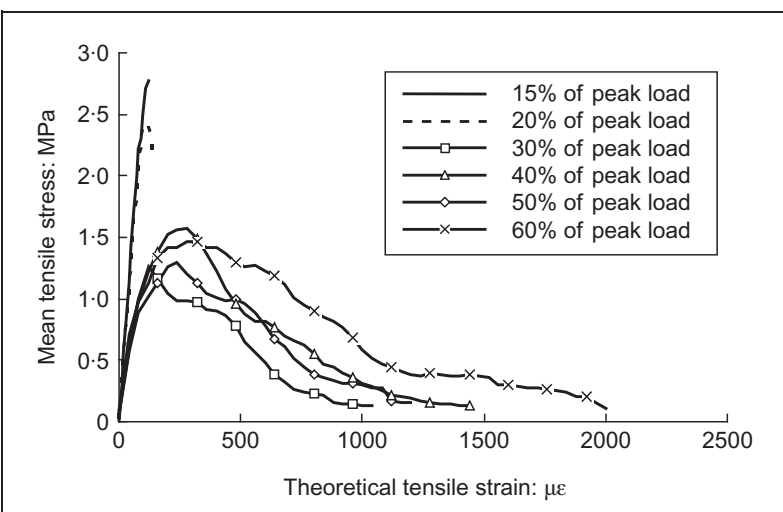

(a)

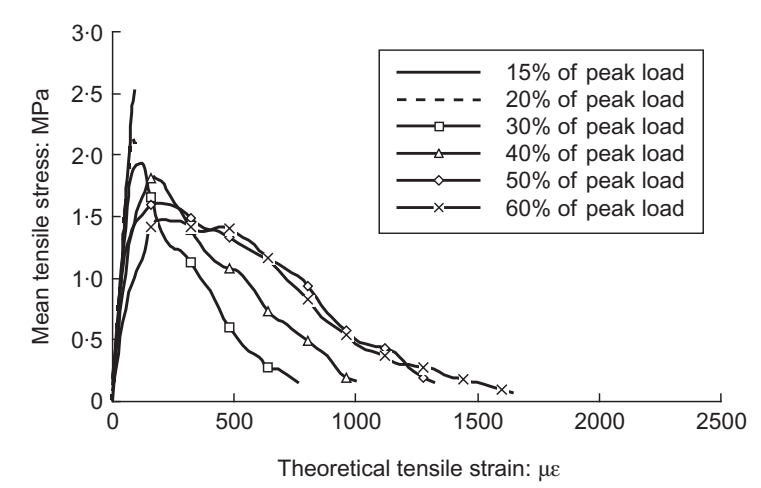

(b)

Figure 6. Curves of mean tensile stress plotted against theoretical tensile strain: (a) beams subjected to point load at mid-span $\left(\rho_{\mathrm{t}}=0.5 \%\right)$; (b) beams subjected to uniformly distributed load $\left(\rho_{\mathrm{t}}=0.5 \%\right)$

the change is not large and, for simplicity, the four curves for applied loads equal to 30, 40, 50 or $60 \%$ of the peak load may be combined into a single curve for the post-crack state. In this study, the single curve for the post-crack state was obtained by arithmetic averaging of the aforementioned four curves. Such averaging was repeated for the other concrete beams studied and the curves so obtained are presented in Figure 7.

It is evident from Figure 7 that among the beams with different $\rho_{\mathrm{t}}$ values under the same type of loading (point load or uniformly distributed load), the respective curves for the postcrack state are fairly close to each other. Hence, the tension reinforcement ratio $\rho_{\mathrm{t}}$ does not appear to have a significant effect on the variation of mean tensile stress with theoretical tensile strain in the post-crack state. On the other hand, the type of loading does seem to have a certain effect: the curves for beams under a point load have lower peaks and longer tails and the curves for beams subjected to a uniformly distributed load have higher peaks and shorter tails.

\subsection{Proposed tensile stress block}

From the mean tensile stress-theoretical tensile strain curves obtained by FE analysis, a tensile stress block may be derived. The numerical procedures for obtaining the mean tensile stress and theoretical tensile strain (explained in the previous section) are completely general and should also be applicable to fibrereinforced concrete beams and beams subjected to combined axial load and bending. However, further manipulation is

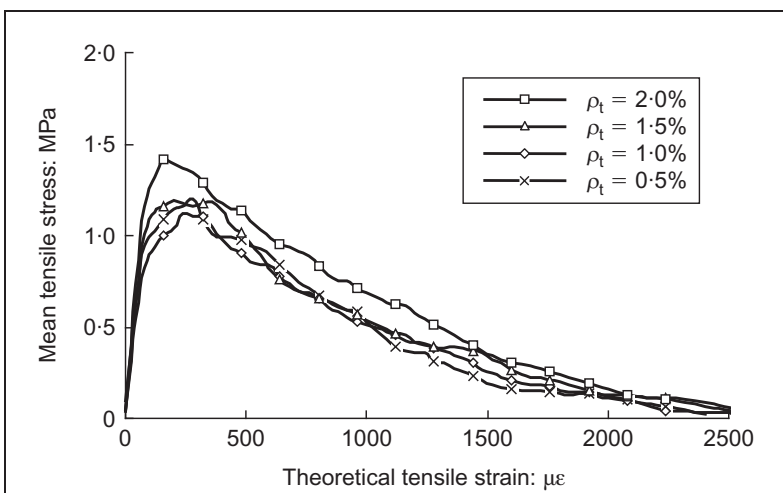

(a)

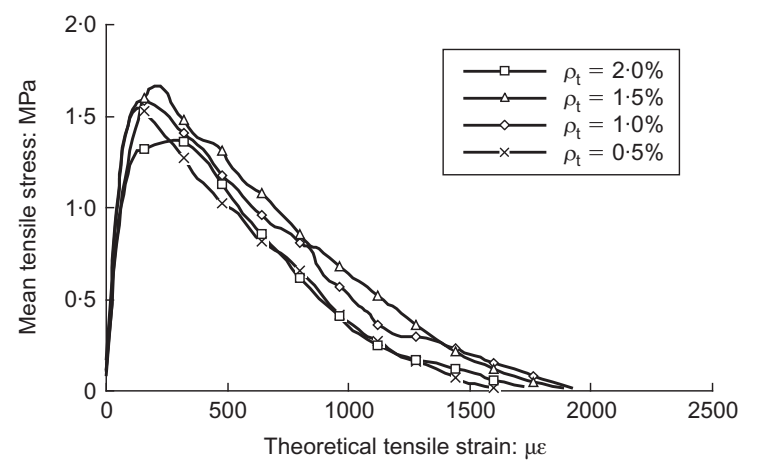

(b)

Figure 7. Averaged curves of mean tensile stress plotted

against theoretical tensile strain: (a) beams subjected to point load at mid-span; (b) beams subjected to uniformly distributed load

needed because the mean tensile stress-theoretical tensile strain curve changes as the concrete cracks or, in other words, the curve obtained after cracking is not quite the same as that before cracking. To deal with this phenomenon, the following strategy is adopted.

Figure 6 shows that before cracking, the mean tensile stresstheoretical tensile strain curve is just an ascending straight line reaching the concrete tensile strength. After cracking, the curve changes to one with a non-linear ascending branch reaching about half the tensile strength of concrete and a descending branch with a long tail. The two distinct forms of the curve before and after cracking are shown schematically in Figure 8(a). During cracking, the form of the curve changes abruptly without a smooth transition. Hence, if tensile stress blocks are to be developed for accurate analysis, there must be one for the pre-crack state and another for the post-crack state. However, traditional practice has been to adopt one tensile stress block for both the pre-crack and post-crack states. Furthermore, from the practical application point of view, it should be more convenient to use just one tensile stress block in the analysis regardless of the stress state. Therefore, if possible, it is preferable to combine the distinct tensile stress blocks into one that can be applied at both the pre-crack and post-crack states without causing significant errors.

It is proposed to combine the two distinct tensile stress blocks shown in Figure 8(a) into the one shown in Figure 8(b). The proposed combined tensile stress block is in the form of a 


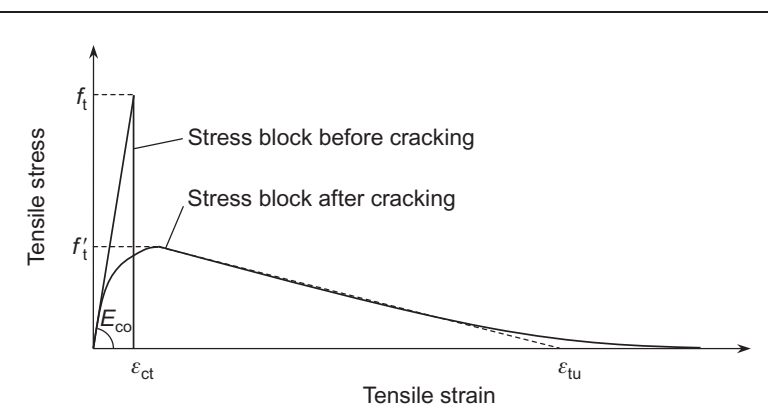

(a)

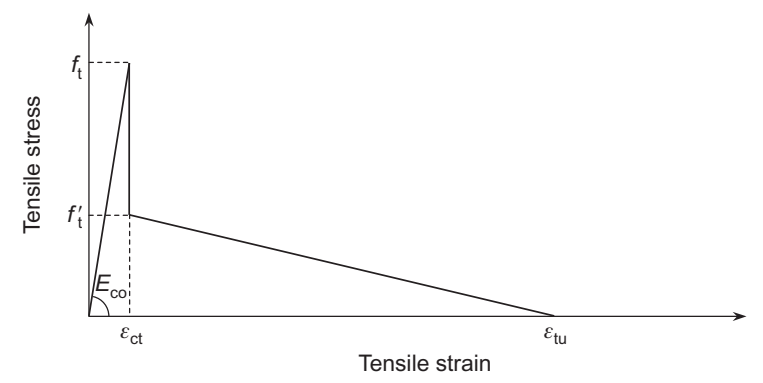

(b)

Figure 8. (a) Distinct stress blocks before and after cracking. (b) Proposed combined tensile stress block

multi-linear tensile stress-strain curve. It has a linear ascending branch and a linear descending branch. In the ascending branch, the tensile stress increases linearly from zero to the tensile strength of the concrete $\boldsymbol{f}_{\mathrm{t}}$ at a gradient equal to the initial elastic modulus of the concrete $\boldsymbol{E}_{\text {co. }}$. In the descending branch, the tensile stress decreases linearly from a certain tensile stress of $\boldsymbol{f}_{\mathrm{t}}^{\prime}$ to zero at an ultimate tensile strain of $\boldsymbol{\varepsilon}_{\mathrm{tu}}$. The values of $\boldsymbol{f}_{\mathrm{t}}^{\prime}$ and $\boldsymbol{\varepsilon}_{\mathrm{tu}}$ are expressed in terms of two dimensionless coefficients, $\alpha_{1}$ and $\alpha_{2}$, as

\begin{tabular}{|c|c|}
\hline $7 \mathrm{a}$ & $\boldsymbol{f}_{\mathrm{t}}^{\prime}=\alpha_{1} \boldsymbol{f}_{\mathrm{t}}$ \\
\hline
\end{tabular}

7b $\boldsymbol{\varepsilon}_{\mathrm{tu}}=\alpha_{2} \boldsymbol{\varepsilon}_{\mathrm{ct}}$

where $\alpha_{1}$ is a coefficient smaller than $1, \alpha_{2}$ is a coefficient greater than 1 and $\boldsymbol{\varepsilon}_{\mathrm{ct}}$ is the tensile strain at which the peak tensile stress occurs (note that $\boldsymbol{\varepsilon}_{\mathrm{ct}}=\boldsymbol{f}_{\mathrm{t}} / \boldsymbol{E}_{\mathrm{co}}$ ).

The equations for the above proposed tensile stress block are

8 a

\begin{tabular}{|c|c|}
\hline $8 b$ & $\boldsymbol{\sigma}=\frac{\alpha_{1} \boldsymbol{f}_{\mathrm{t}}\left(\alpha_{2} \boldsymbol{\varepsilon}_{\mathrm{ct}}-\boldsymbol{\varepsilon}\right)}{\left(\alpha_{2} \boldsymbol{\varepsilon}_{\mathrm{ct}}-\boldsymbol{\varepsilon}_{\mathrm{ct}}\right)}$ for $\boldsymbol{\varepsilon}_{\mathrm{ct}}<\boldsymbol{\varepsilon} \leqslant \alpha_{2} \boldsymbol{\varepsilon}_{\mathrm{ct}}$ \\
\hline
\end{tabular}

$8 c$

The actual tensile stresses induced in the beam section depend on the theoretical tensile strains in the beam section, especially the maximum theoretical tensile strain at the extreme tension

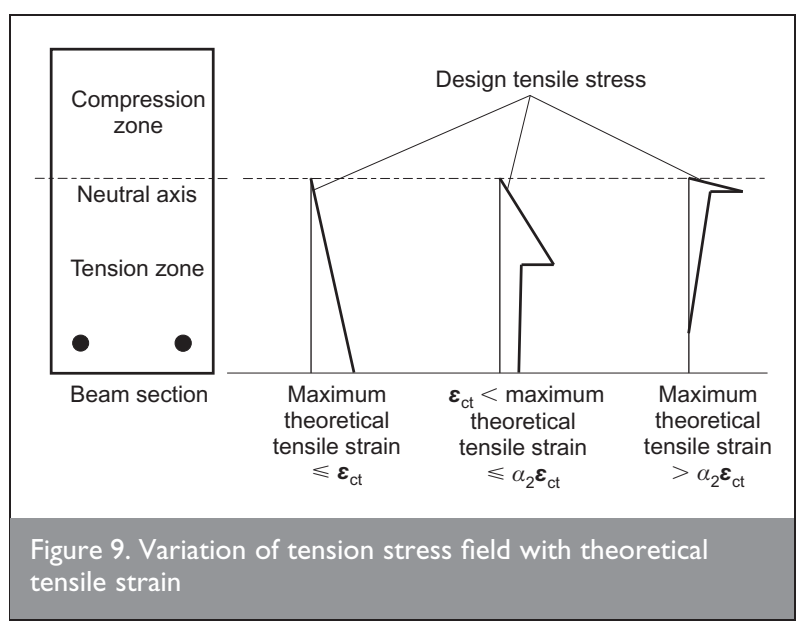

fibre, as shown in Figure 9. If the maximum theoretical tensile strain is smaller than $\boldsymbol{\varepsilon}_{\mathrm{ct}}$, then the tensile stress block representing the tension stress field in the tension zone is a triangular block. If the maximum theoretical tensile strain is larger than $\boldsymbol{\varepsilon}_{\mathrm{ct}}$ but smaller than $\alpha_{2} \boldsymbol{\varepsilon}_{\mathrm{ct}}$, then the tensile stress block representing the tension stress field consists of a triangular block for the pre-crack tension and a trapezoidal block for the post-crack tension. Lastly, if the maximum theoretical tensile strain is larger than $\alpha_{2} \boldsymbol{\varepsilon}_{\mathrm{ct}}$, then the tensile stress block is a triangular block for the pre-crack tension, a triangular block for the post-crack tension and a zero stress block for concrete no longer capable of carrying any tension.

The values of $\alpha_{1}$ and $\alpha_{2}$ may be determined by referring back to Figure 7. From the curves presented in the figure, it has been calculated that for beams subjected to a point load, $\alpha_{1}$ ranges from 0.37 to 0.47 with a mean of 0.41 and $\alpha_{2}$ is $17 \cdot 2-19 \cdot 7$ with a mean of $18 \cdot 2$; for beams subjected to a uniformly distributed load, $\alpha_{1}$ is $0.45-0.55$ with a mean of 0.51 and $\alpha_{2}$ is $13 \cdot 0-15 \cdot 8$ with a mean of $14 \cdot 2$. For simplicity, the minor effects of the reinforcement ratio may be neglected. Hence, for beams subjected to a point load, $\alpha_{1}$ and $\alpha_{2}$ may be taken as $0 \cdot 4$ and 18 , respectively, and for beams subjected to a uniformly distributed load, $\alpha_{1}$ and $\alpha_{2}$ may be taken as 0.5 and 14 , respectively.

The use of just one tensile stress block for both the pre-crack and post-crack states would inevitably introduce errors in the structural analysis, but it is considered that the errors so introduced should be small. At the pre-crack state, the tensile stress block is exactly the same as the mean tensile stresstheoretical tensile strain curve before cracking and thus there should be no errors introduced. At the post-crack state, the tensile stress block would overestimate the tensile stresses at the locations where the theoretical tensile strain is smaller than $\boldsymbol{\varepsilon}_{\mathrm{ct}}$ but these locations should be quite close to the neutral axis and thus the errors in the bending moment so introduced should be small, as will be shown in part 2 of this paper (Lam et al., 2009).

\section{CONCLUSIONS}

The tension stress fields in the concrete of reinforced concrete beams at both the pre-crack and post-crack states have been analysed using an FE method that takes into account: 
(a) the cracking and non-linear biaxial behaviour of the concrete

(b) the elastic, plastic and strain-hardening behaviour of the steel reinforcement

(c) the non-linear bond stress-slip behaviour of the steel reinforcement-concrete bond.

The results of the FE analysis indicate that, after cracking, the tensile stress in concrete varies not only with depth but also in the longitudinal direction between cracks. On the other hand, the bond between the reinforcement and concrete is always transferring tensile stresses to the uncracked concrete, leading to a gradual increase in the tensile stress in the concrete with distance from the nearest crack. However, the tensile force induced in the concrete is generally larger than the tensile force transferred through the bond, indicating that, along with the stress transfer through the bond, the curvature of the beam should also induce significant tensile forces in the tension zones of the uncracked sections.

For the beams analysed, it was found that, in general, before cracking, the mean tensile stress-theoretical tensile strain curve is a straight line ascending to the tensile strength of concrete. After cracking, the curve comprises a non-linear ascending branch reaching about half the tensile strength and a descending branch with a long tail. Both the applied load level and the tension reinforcement ratio have little effect on the mean tensile stress-theoretical tensile strain curve. However, the type of loading (point load or uniformly distributed load) does have an influence. Although in theory, two distinct tensile stress blocks - one for the pre-crack state and another for the post-crack state - should be adopted, it is proposed for convenience in practical applications to combine the two tensile stress blocks into one that can be applied at all crack states. Based on the numerical results obtained, a combined tensile stress block defined in terms of two parameters, $\alpha_{1}$ and $\alpha_{2}$, which are dependent on the type of loading, was derived. Its validity and applicability to section and member analysis will be demonstrated in part 2 of this paper (Lam et al., 2009).

\section{REFERENCES}

ACI (American Concrete Institute) (2008) Building Code Requirements for Structural Concrete and Commentary, Manual of Concrete Practice. ACI, Farmington Hills, MI, ACI 318M-08.

ASCE (American Society of Civil Engineers) (1982) State-ofthe-Art Report on Finite Element Analysis of Reinforced Concrete Structures. ASCE, New York.

Beeby AW, Scott RH and Jones AEK (2005) Revised code provisions for long-term deflection calculations. Proceedings of the Institution of Civil Engineers, Structures and Buildings 158(1): 71-75.

BSI (British Standards Institution) (1985) Structural Use of Concrete, Part 2: Code of Practice for Special Circumstances. BSI, London, BS 8110.

Choi CK and Cheung SH (1996) Tension stiffening model for planar reinforced concrete members. Computers and Structures 59(1): 179-190.

CEB (Comité Euro-International du Béton) (1993) CEB-FIP Model Code 1990: Model Code for Concrete Structures. Thomas Telford, London.
Creazza G and Di Marco R (1993) Bending moment-mean curvature relationship with constant axial load in the presence of tension stiffening. Materials and Structures 26(4): 196-206.

Fields K and Bischoff PH (2004) Tension stiffening and cracking of high-strength reinforced concrete tension members. ACI Structural Journal 101(4): 447-456.

Floegl H and Mang HA (1982) Tension stiffening concept based on bond slip. ASCE Journal of Structural Engineering Division 108(12): 2681-2701.

Gilbert RI and Warner RF (1978) Tension stiffening in reinforced concrete slabs. ASCE Journal of Structural Engineering Division 104(12): 1885-1900.

Goodman RE, Taylor RL and Brekke TL (1968) A model for the mechanics of jointed rock. ASCE Journal of Soil Mechanics and Foundations Division 94(3): 637-659.

Guo ZH and Zhang XQ (1987) Investigation of complete stress-deformation curves of concrete in tension. ACI Materials Journal 84(4): 278-285.

Gupta AK and Maestrini SR (1989) Post-cracking behavior of membrane reinforced concrete elements including tensionstiffening. ASCE Journal of Structural Engineering 115(4): 957-993.

Gupta AK and Maestrini SR (1990) Tension-stiffness model for reinforced concrete bars. ASCE Journal of Structural Engineering 116(3): 769-790.

He XG and Kwan AKH (2001) Modeling dowel action of reinforcement bars for finite element analysis of concrete structures. Computer and Structures 79(6): 595-604.

Hughes BP (2008) Early-age concrete crack control - is EC2 right or wrong? Structural Engineer 86(15): 32-37.

Jiang DH, Shah SP and Andonian AT (1984) Study of the transfer of tensile forces by bond. ACI Journal 81(3): 251 529.

Kaklauskas G and Ghaboussi J (2001) Stress-strain relations for cracked tensile concrete from RC beam tests. ASCE Journal of Structural Engineering 127(1): 64-73.

Kupfer HB and Gerstle KH (1973) Behaviour of concrete under biaxial stresses. ASCE Journal of Engineering Mechanics Division 99(4): 853-866.

Lam JYK, Ng PL and Kwan AKH (2009) Tension stiffening in reinforced concrete eams. Part 2: section and member analysis. Proceedings of the Institution of Civil Engineers, Structures and Buildings 163(1): 29-39

Liauw TC and Kwan KH (1982) Nonlinear analysis of multistorey infilled frames. Proceedings of the Institution of Civil Engineers, Part 2 73: 441-456.

Link RA, Elwi AE and Scanlon A (1989) Biaxial tension stiffening due to generally oriented reinforcing layers. ASCE Journal of Engineering Mechanics 115(8): 1647-1662.

Mander JB (1984) Seismic design of bridge piers. PhD thesis, University of Canterbury, New Zealand.

Massicotte B, Elwi AE and MacGregor JG (1990) Tensionstiffening model for planar reinforced concrete members. ASCE Journal of Structural Engineering 116(11): 3039 3058.

Ng PL (2007) Constitutive modelling and finite element analysis of reinforced concrete structures. $\mathrm{PhD}$ thesis, University of Hong Kong.

Piyasena R, Loo YC and Fragomeni S (2002) Tension stiffening effects in deflection of reinforced concrete beams. In Advances in Mechanics of Structures and Materials (Loo Y-C, 
Chowdry SH and Fragomeni, eds). Swets \&t Zeitlinger, Lisse, pp. 205-210.

Polak MA and Blackwell KG (1998) Modeling tension in reinforced concrete members subjected to bending and axial load. ASCE Journal of Structural Engineering 124(9): 1018 1024.

Prakhya GKV and Morley CT (1990) Tension-stiffening and moment-curvature relations of reinforced concrete elements. ACI Structural Journal 87(5): 597-605.

Saenz LP (1964) Discussion of 'Equation for the stress-strain curve of concrete' by Desayi and Krishnan. ACI Journal 61(9): 1229-1235.
Scott RH (1983) The short-term moment-curvature relationship for reinforced concrete beams. Proceedings of the Institution of Civil Engineers, Part 2 75: 725-734.

Torres Ll, Lopez-Almansa F and Bozzo LM (2004) Tensionstiffening model for cracked flexural concrete members. ASCE Journal of Structural Engineering 130(8): 1242-1251.

Wollrab E, Kulkarni SM, Ouyang C and Shah SP (1996) Response of reinforced concrete panels under uniaxial tension. ACI Structural Journal 93(6): 648-657.

Wu Z, Yoshikawa H and Tanabe T (1991) Tension stiffness model for cracked reinforced concrete. ASCE Journal of Structural Engineering 117(3): 715-732.

\section{What do you think?}

To discuss this paper, please email up to 500 words to the editor at journals@ice.org.uk. Your contribution will be forwarded to the author(s) for a reply and, if considered appropriate by the editorial panel, will be published as discussion in a future issue of the journal.

Proceedings journals rely entirely on contributions sent in by civil engineering professionals, academics and students. Papers should be 2000-5000 words long (briefing papers should be 1000-2000 words long), with adequate illustrations and references. You can submit your paper online via www.ice.org.uk/journals, where you will also find detailed author guidelines. 